\title{
THREE-DIMENSIONAL SIMULATION ANALYSIS OF A FULL-SCALE 5-STORY BUILDING WITH STEEL DAMPERS
}

\author{
Naohiro NAKAMURA ${ }^{1}$, Takuya SUZUKI $^{1}$, Soshi NAKAMURA ${ }^{1}$ \\ ${ }^{1}$ Research \& Development Institute, Takenaka Corporation (nakamura.naohiro@takenaka.co.jp)
}

\begin{abstract}
Recently, vibration control devices are often adopted in Japanese buildings. Then, the seismic behavior of the buildings with them should be seized in the design stage accurately. However, that accuracy is not enough because the test data and analyses of the full-scale building are insufficient. This paper presents the 3 dimensional simulation of the experiment of the full-scale 5-story steel building using steel dampers conducted by E-Defense in 2009. Although the analysis results agreed the test results almost well, some differences were seen. Therefore, additional analyses were performed to study the effect of used models and parameters.
\end{abstract}

Keywords: 3 dimensional analysis, E-defense, Full-scale experiment, Steel damper

\section{INTRODUCTION}

Analysis methods to accurately estimate the behavior of buildings when earthquakes occur is very important for improving the seismic safety of such buildings. Recently, the use of damping devices has increased significantly and there is a particular need to appropriately evaluate the behavior of buildings with such devices during earthquakes in the design stage. At present, however, the accuracy of the analysis evaluations is not sufficient. One reason is that the accuracy of current analysis methods has not been appropriately verified because there is very limited data on the behavior of actual buildings during earthquakes.

Many types of shaking table test of large structures are performed at the "3 Dimensional Full-Scale Earthquake Testing Facility" (nicknamed "E-Defense") operated by the National Research Institute of Earth Science and Disaster Prevention (NIED). In this study, simulations using 3 dimensional analysis models were conducted in 2009 on shaking table test of a 5-story steel-frame structure with steel dampers.

These tests were used by the E-Defense Steel Structure Research Committee for a blind analysis contest. The analysis in this paper was conducted in order to participate in this contest. The results of the analysis (hereinafter "prediction analysis") correspond favorably to the test results announced afterward by the committee. However, the suitability of the parameters and models used in the prediction analysis and the influence they had on the responses remain unclear. Hence, we conducted additional analysis and studies on these models and parameters. 
In this paper, outlines of the test are shown and the utilized analysis model is explained. Next, the analysis results are compared with the test results. Then, the additional analyses, concerning with the hysteresis curve of the dampers and the beam-end stiffness of the frame, are investigated.

\section{OUTLINE OF TEST}

The outline of the shaking table test was shown by Kasai et al. [1] and Hikino et al. [2]. The tests were performed setting various types of dampers in order of steel, viscous, oil and viscoelastic on a full scale 5-story steel-frame structure. At the end, the test using the structure only (without dampers) was done. All the parts except the dampers were used throughout the test. This paper investigated the first test conducted with the steel dampers installed in the structure.

Figures 1 to 3 show the outline view, a plan and elevations of the test specimen, respectively. Table 1 provides the outline of the test specimen. Table 2 shows the weight for the specimen. Tables 3 to 4 show the lists of cross section sizes for both all girders and all columns, respectively.

Three-directional components of the 1995 Hyogo-ken-nanbu Earthquake Takatori wave [3] were inputted into the specimen, gradually increasing from $15 \%$ to $100 \%$. Figure 4 shows the acceleration time history of the wave.

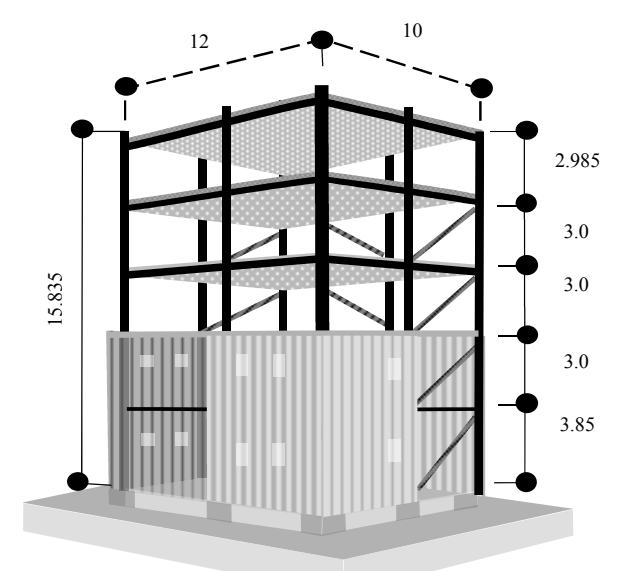

Figure.1 Outline view of the test specimen

Table 1 Outline of test specimen

\begin{tabular}{|c|c|}
\hline Structure & 5-story steel building \\
\hline Height & $15.835 \mathrm{~m}$ \\
\hline Plane shape & $12.0 \mathrm{~m} \times 10.0 \mathrm{~m}$ \\
\hline Mass & 580 ton \\
\hline The number of damper & $12(3$ at Floor) \\
\hline
\end{tabular}


Table 2 Weight for test specimen (Unit: $\mathrm{kN}$ )

\begin{tabular}{|c|c|c|c|c|c|c|c|}
\hline Floor & Floor & $\begin{array}{c}\text { Steel } \\
\text { frame }\end{array}$ & $\begin{array}{c}\text { Exterior } \\
\text { Wall }\end{array}$ & $\begin{array}{c}\text { Interior } \\
\text { wall }\end{array}$ & $\begin{array}{c}\text { Live } \\
\text { load }\end{array}$ & Others & $\begin{array}{c}\text { Total } \\
\text { weight }\end{array}$ \\
\hline $\mathrm{RF}$ & 963.4 & 111.6 & 127.8 & 20.3 & 81.7 & 150.0 & 1454.8 \\
\hline $5 \mathrm{~F}$ & 436.2 & 99.5 & 100.3 & 26.5 & 98.8 & 37.5 & 798.8 \\
\hline $4 \mathrm{~F}$ & 436.2 & 117.4 & 100.3 & 26.5 & 98.8 & 37.5 & 816.7 \\
\hline $3 \mathrm{~F}$ & 436.2 & 122.7 & 100.3 & 26.5 & 98.8 & 37.5 & 822.0 \\
\hline $2 \mathrm{~F}$ & 436.2 & 131.3 & 108.8 & 28.7 & 98.8 & 37.5 & 841.3 \\
\hline Total & 2708.2 & 582.5 & 537.5 & 128.5 & 476.9 & 300.0 & 7433.6 \\
\hline
\end{tabular}

Table 3 List of cross section sizes for all girders

\begin{tabular}{|c|c|c|c|c|c|}
\hline Floor & G1(Full portion) & G2(End portion) & G2(Center portion) & G3(End portion) & G3(Center Portion) \\
\hline $\mathrm{RF}$ & H-400x200x9x 12 & BH-400x $200 \times 9 \times 12$ & H-400x $200 \times 9 \times 12$ & BH-400x $200 \times 12 \times 16$ & H-400x $200 \times 9 \times 12$ \\
\hline $5 \mathrm{~F}$ & $\mathrm{BH}-400 \times 200 \times 12 \times 16$ & $\mathrm{BH}-400 \times 200 \times 12 \times 16$ & $\mathrm{H}-400 \times 200 \times 9 \times 12$ & $\mathrm{BH}-400 \times 200 \times 12 \times 16$ & $\mathrm{H}-400 \times 200 \times 9 \times 12$ \\
\hline $4 \mathrm{~F}$ & BH- $400 \times 200 \times 12 \times 19$ & BH-400x $200 \times 12 \times 19$ & $\mathrm{H}-400 \times 200 \times 9 \times 16$ & BH-400x $200 \times 12 \times 19$ & $\mathrm{H}-400 \times 200 \times 9 \times 16$ \\
\hline $3 \mathrm{~F}$ & $H-400 \times 200 \times 12 \times 22$ & BH-400x $200 \times 12 \times 19$ & $\mathrm{H}-400 \times 200 \times 9 \times 16$ & $\mathrm{BH}-400 \times 200 \times 12 \times 19$ & $\mathrm{H}-400 \times 200 \times 9 \times 16$ \\
\hline $2 \mathrm{~F}$ & H- $400 \times 200 \times 12 \times 22$ & BH-400x $200 \times 12 \times 19$ & $\mathrm{H}-400 \times 200 \times 9 \times 16$ & BH-400x $200 \times 12 \times 19$ & $\mathrm{H}-400 \times 200 \times 9 \times 16$ \\
\hline $1 \mathrm{~F}$ & BH- $900 \times 500 \times 16 \times 28$ & \multicolumn{2}{|c|}{ BH- $900 \times 500 \times 16 \times 28$} & \multicolumn{2}{|c|}{ BH- $900 \times 500 \times 16 \times 28$} \\
\hline Floor & G11(Full portion) & G12(End portion) & G12(Center portion) & G13(End portion) & G13(Center Portion) \\
\hline $\mathrm{RF}$ & $\mathrm{H}-400 \times 200 \times 9 \times 12$ & BH-400x200x9x12 & $\mathrm{H}-400 \times 200 \times 9 \times 12$ & BH-400x200x9x12 & $\mathrm{H}-400 \times 200 \times 9 \times 12$ \\
\hline $5 \mathrm{~F}$ & BH- $400 \times 200 \times 12 \times 16$ & BH- $400 \times 200 \times 12 \times 16$ & $\mathrm{H}-400 \times 200 \times 9 \times 12$ & BH- $400 \times 200 \times 12 \times 16$ & H-400x $200 \times 9 \times 12$ \\
\hline $4 \mathrm{~F}$ & BH- $400 \times 200 \times 12 \times 16$ & BH- $400 \times 200 \times 12 \times 19$ & $\mathrm{H}-400 \times 200 \times 9 \times 16$ & BH- $400 \times 200 \times 12 \times 19$ & $\mathrm{H}-400 \times 200 \times 9 \times 16$ \\
\hline $3 \mathrm{~F}$ & H- $400 \times 200 \times 12 \times 19$ & BH-400x $200 \times 12 \times 19$ & $\mathrm{H}-400 \times 200 \times 9 \times 16$ & BH- $400 \times 200 \times 12 \times 19$ & $H-400 \times 200 \times 9 \times 16$ \\
\hline $2 \mathrm{~F}$ & H- $400 \times 200 \times 12 \times 22$ & $\mathrm{BH}-400 \times 200 \times 12 \times 19$ & $\mathrm{H}-400 \times 200 \times 9 \times 16$ & $\mathrm{BH}-400 \times 200 \times 12 \times 19$ & H-400x200x9x16 \\
\hline $1 \mathrm{~F}$ & BH- $900 \times 500 \times 16 \times 28$ & \multicolumn{2}{|c|}{ BH- $900 \times 500 \times 16 \times 28$} & \multicolumn{2}{|c|}{ BH- $900 \times 500 \times 16 \times 28$} \\
\hline
\end{tabular}

Table 4 List of cross section sizes for all columns

\begin{tabular}{|c|l|l|l|}
\hline Story & \multicolumn{1}{|c|}{$\mathrm{C} 1$} & \multicolumn{1}{c|}{$\mathrm{C} 2$} & $\mathrm{C} 3$ \\
\hline 5 & $\square-350 \times 350 \times 12 \times 12$ & $\square-350 \times 350 \times 12 \times 12$ & $\square-350 \times 350 \times 12 \times 12$ \\
\hline 4 & $\square-350 \times 350 \times 12 \times 12$ & $\square-350 \times 350 \times 12 \times 12$ & $\square-350 \times 350 \times 12 \times 12$ \\
\hline 3 & $\square-350 \times 350 \times 16 \times 16$ & $\square-350 \times 350 \times 16 \times 16$ & $\square-350 \times 350 \times 19 \times 19$ \\
\hline 2 & $\square-350 \times 350 \times 16 \times 16$ & $\square-350 \times 350 \times 19 \times 19$ & $\square-350 \times 350 \times 19 \times 19$ \\
\hline 1 & $\square-350 \times 350 \times 19 \times 19$ & $\square-350 \times 350 \times 22 \times 22$ & $\square-350 \times 350 \times 22 \times 22$ \\
\hline
\end{tabular}




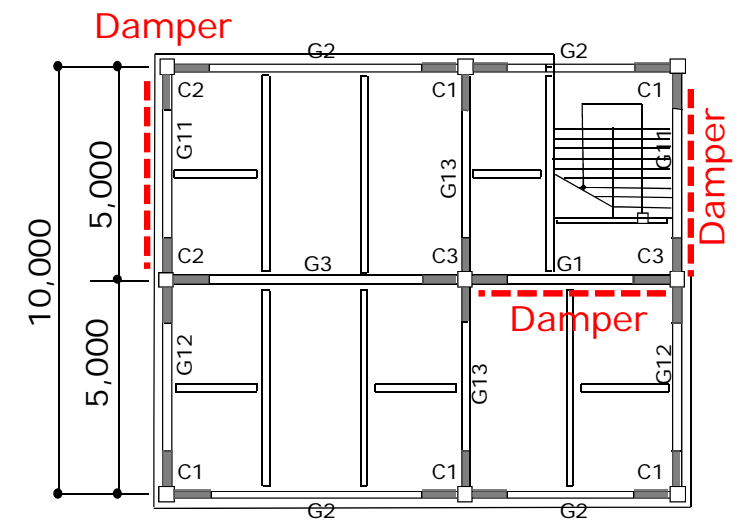

Figure.2 Plan of the specimen

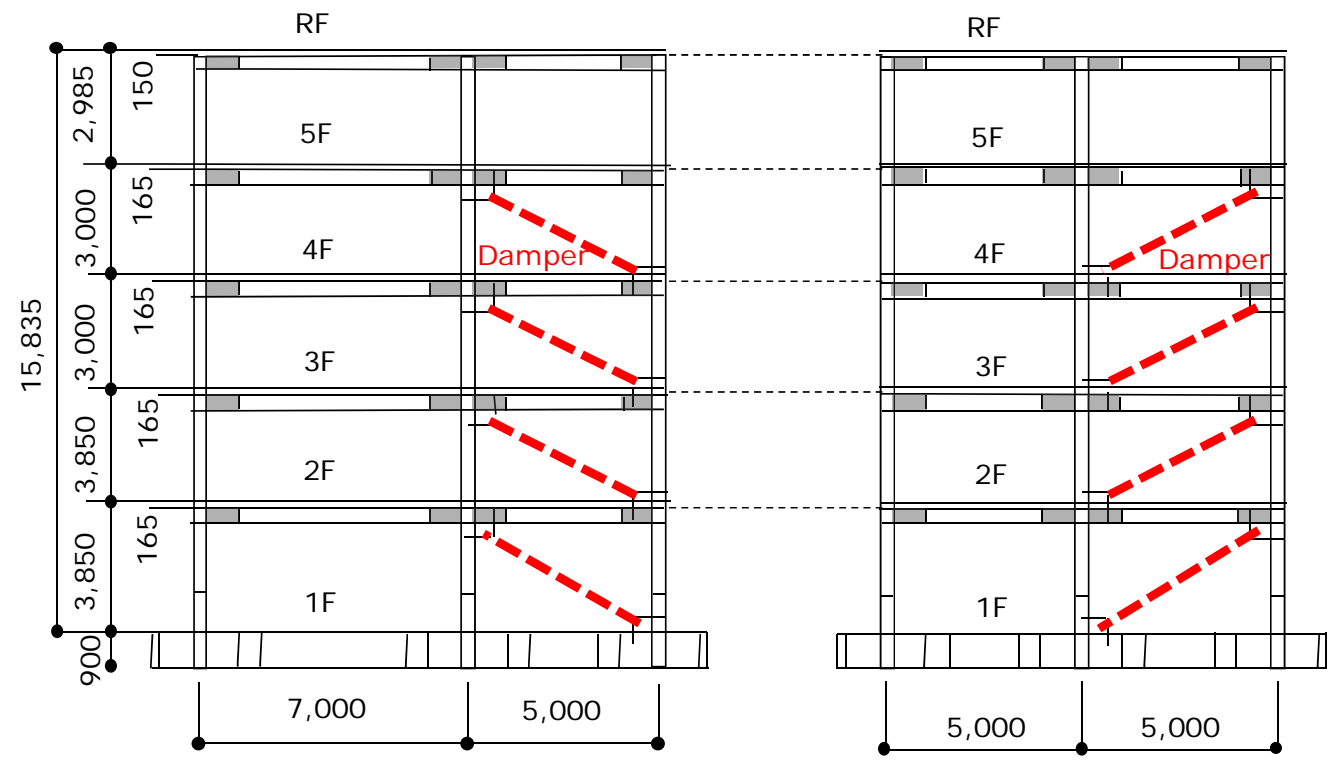

(a) $\mathrm{X}$ direction

(b) Y direction

Figure.3 Elevations of the specimen 


\section{ANALYSIS MODEL}

The following is the outline of the set analysis model for prediction analysis.

\subsection{Basic Policy}

Table 5 lists the modeled members and element types of the analysis model shown in Figure 5. The modeled members are columns, beams, floor slabs, partition walls, and steel dampers. The external wall elements were not modeled. All parts except the dampers are modeled as linear elements, because the main frames were estimated to remain within their elastic range for the input seismic motion in this study. The model comprises a total of 488 nodal points, 451 elements, and 1,534 degrees of freedom.

The time interval for the analysis was $0.002 \mathrm{~s}$ and the Newmark-beta method with $\beta=$ 0.25 and $\gamma=0.5$ was used as the time integration method.

Table 6 shows the first eigenperiods in each direction obtained from the eigenvalue analysis of the model. The eigenperiods in both the X-and Y-directions fell below 0.77 times when dampers were provided. This corresponds to a 1.7-fold increase in the overall stiffness.

Table 5 Parts and element types of analysis model

\begin{tabular}{|c|c|c|}
\hline Parts & Element Type & Remarks \\
\hline Columns and beams & Beam & Linear \\
\hline Floor slabs & Shell & Linear \\
\hline $\begin{array}{c}\text { Non-structural materials } \\
\text { (Partition walls) }\end{array}$ & Shell & Linear \\
\hline Dampers (Plastic parts) & Truss & Non-linear \\
\hline Dampers (Elastic parts) & Beam & Linear \\
\hline
\end{tabular}

\subsection{Total Frame Modeling}

The columns and beams were modeled with linear beam elements but the connection panel zones were not modeled. As a result, the stiffness of the connection at panel zones is taken into account as the gain in stiffness of the beam-end elements. The horizontal haunches of the beam flanges, and the gusset and rib plates for attaching the dampers were also expected to increase the stiffness. We considered the above increases in stiffness as increases in the bending stiffness in the strong axis of the beam-end elements (shown as gray parts in Figures 2 and 3). Some research was conducted on the influence on horizontal haunches and damper attachment sections as a part of the series of studies concerning this seismic test [4], [5]. The amount of the increase was set to match the main frame stiffness obtained from these studies. The value, $5.5 \times 106 \mathrm{kN} / \mathrm{rad}$, which was shown in Figure 6 of Yonetani's paper was used as the stiffness. From above, the beam-ends were modeled with the same cross-sections as the beam center parts and only the area moment of inertia of the strong axis was increased 5 times. 
The floor slabs were modeled using linear shell elements. The slab stiffness value was calculated assuming that the full slab cross-section was concrete. The slab elements were placed at the center position of the slab thickness. The nodes of the slab elements were connected with those of the beam elements by rigid elements. The partition walls were also modeled with linear shell elements. The wall stiffness was calculated based on the results of the test [6] in which the same scale of partition walls were shaken. From the study, the secant stiffness of the partition walls was obtained as 1.5/1000 times of concrete stiffness at the $1 / 100$ story drift angle.

The stiffness proportional damping was used, and the damping ratio for the frame was set at $2 \%$ at the period of $0.470 \mathrm{sec}$, which was the average of the first eigenperiods in the Xand Y-directions.

Table 6 First eigenperiods of analysis model

\begin{tabular}{|c|c|c|}
\hline & $X$ direction & Y direction \\
\hline Frame & $0.603 \mathrm{sec}$ & $0.617 \mathrm{sec}$ \\
\hline Frame with damper & $0.466 \mathrm{sec}$ & $0.474 \mathrm{sec}$ \\
\hline
\end{tabular}

\subsection{Damper Modeling}

The hysteresis curve of the steel dampers is set by following rules. An increase of yield stress along with an increase in the strain amplitude is set by the quadratic functions. The Bauschinger effect was represented through the Menegotto-Pinto models [7]. The hysteresis curve is shown in Figure 6. The hysteresis model of Menegotto-Pinto model is represented by following equations.

$$
\begin{aligned}
& \sigma^{\prime}=p \varepsilon^{\prime}+\frac{(1-p) \varepsilon^{\prime}}{\left(1+\varepsilon^{\prime R}\right)^{1 / R}} \\
& \varepsilon^{\prime}=\frac{\varepsilon-\varepsilon_{r}}{\varepsilon_{0}-\varepsilon_{r}} \\
& \sigma^{\prime}=\frac{\sigma-\sigma_{r}}{\sigma_{0}-\sigma_{r}} \\
& R=R_{0}-\frac{a_{1} \xi}{a_{2}+\xi}
\end{aligned}
$$

where,

$\varepsilon, \sigma:$ Strain and stress

$\varepsilon_{r} \quad \sigma_{r}:$ Strain and stress at reverse point

$\varepsilon_{0} \sigma_{0}:$ Strain and stress at bilinear yield point

$p$ : Secondary stiffness ratio

$a_{1}, a_{2} R_{0}$ : Curve parameter

$\xi$ : Plastic strain between reverse point and experienced maximum deformation point 
The bilinear yield point $\left(\varepsilon_{0}, \sigma_{0}\right)$ is the intersection of the yield curve function and the line from reverse point. Yield curve functions are following.

$$
\sigma=f(\varepsilon)= \begin{cases} \pm k_{2} \cdot \varepsilon^{2}+k_{1} \cdot \varepsilon \pm k_{0} & (\varepsilon>0) \\ \pm k_{2} \cdot \varepsilon^{2}-k_{1} \cdot \varepsilon \pm k_{0} & (\varepsilon<0)\end{cases}
$$

where $k_{0}, k_{1}$ and $k_{2}$ are yield curve coefficients.

Table 7 Parameters for Menegotto-Pint model

\begin{tabular}{|c|c|}
\hline Parameter & Value \\
\hline Yield curve zero-order coefficient $k_{0}\left(\mathrm{kN} / \mathrm{m}^{2}\right)$ & 320000 \\
\hline Yield curve first-order coefficient $k_{1}\left(\mathrm{kN} / \mathrm{m}^{2}\right)$ & 50000 \\
\hline Yield curve second-order coefficient $k_{2}\left(\mathrm{kN} / \mathrm{m}^{2}\right)$ & -400 \\
\hline Secondary stiffness ratio $\mathrm{p}$ & 0.005 \\
\hline Curve parameter R0 & 7 \\
\hline Curve parameter a1 & 6 \\
\hline Curve parameter a 2 & 0.009 \\
\hline
\end{tabular}
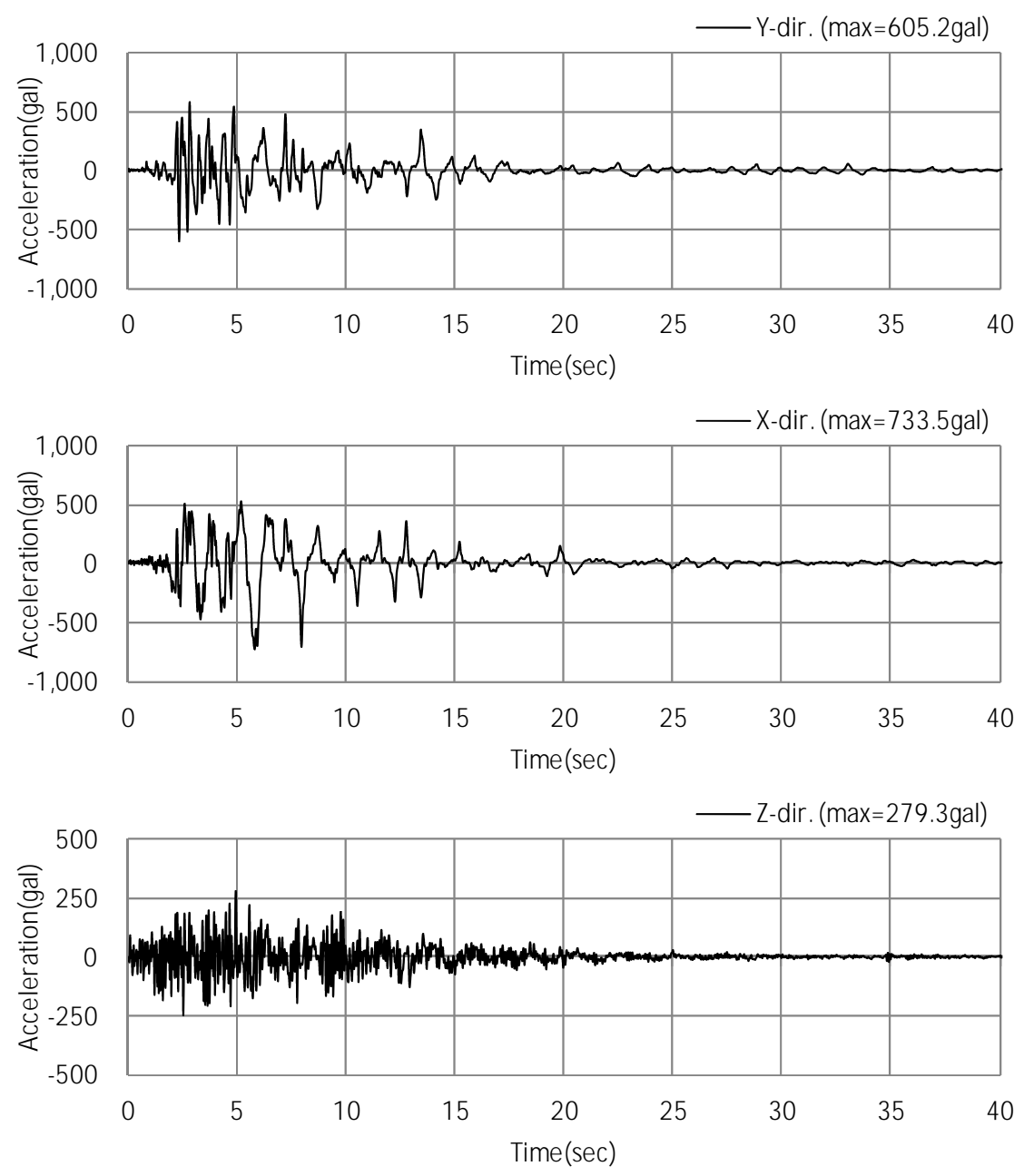

Figure 4 Acceleration time history of Takatori wave 


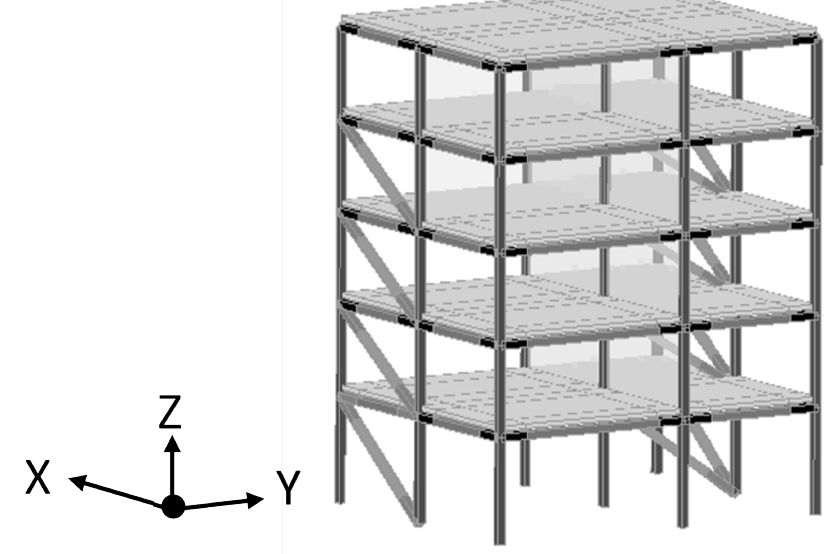

Figure 5 Analysis model

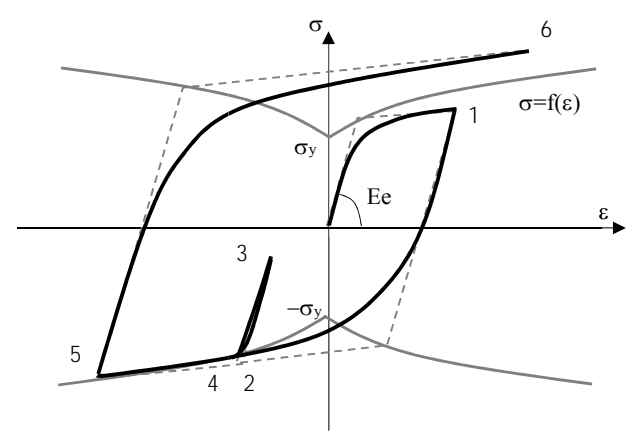

Figure $6 \mathrm{H}$ ysteresis curve of steel damper

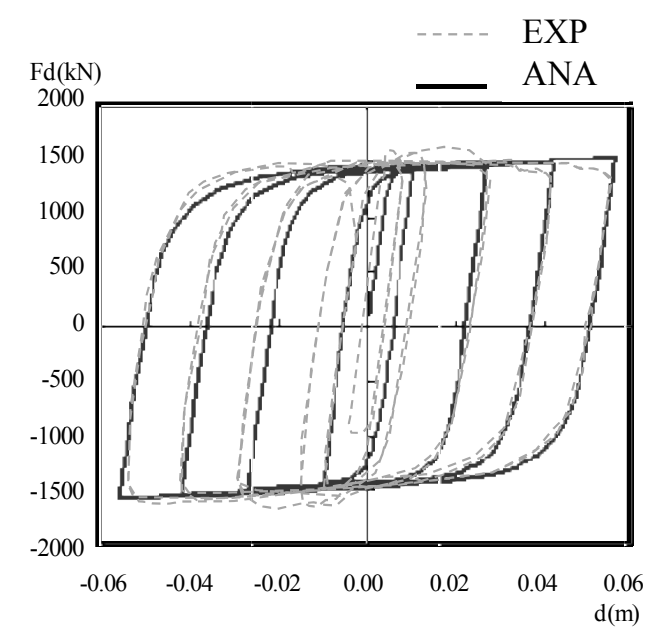

Figure 7 Hysteresis curve used in the analysis 
Besides the initial stiffness (linear constant), this study considered the following parameters: three parameters $\left(k_{0}, k_{1}, k_{2}\right)$ as coefficients of yield curve functions, one parameter $(p)$ for determining the secondary slope of the bilinear curve, which is indicated by the dotted line in Figure 6, and three parameters $\left(a_{1}, a_{2}, R_{0}\right)$ for determining the Menegotto-Pinto model curvature-

These parameters were determined according to dynamic test results in the "Steel Damper Tests for the Blind Analysis Contest" by NIED [8] distributed beforehand. Figure 7 shows the hysteresis model set by using parameters in Table 7. The hysteresis model is defined as the stress-strain behavior, and the same model is used for all the dampers.

\section{ANALYSIS RESULTS}

The Hyogo-ken-nanbu Earthquake Takatori wave was used as the input seismic motion for the prediction analysis. In order to replicate the test, the wave was inputted repeatedly at $15 \%, 40 \%, 50 \%, 70 \%$, and $100 \%$ with 5 second rest between each wave. Figures 8 and 9 show the maximum response values (displacement and acceleration) at each floor and the axial force of the dampers at the first and fourth floors, for $15 \%$ input. The analysis results corresponded fairly well with the test results in both X-and Y-directions. It was observed that all members of the structural frame include the dampers stayed within the linear region during test for $15 \%$ input.

Figures 10 and 11 show those for $100 \%$ input. Although the analysis results show relatively good agreement with the test results totally, the maximum acceleration in the Ydirection shows some differences between the analysis and test results.

Figure 12 describes the relation between the axial force and axial displacement of the steel dampers in the first floor. As can be seen, the dampers stayed within the linear range for the $15 \%$ input wave but exceeded the linear range for the $100 \%$ input wave for both the analysis results and the test results.

The Menegotto-Pinto model used in this analysis replicated well the non-linear behavior of the steel dampers, and thus, it is considered that the analysis matches well the test results. The test results in Figures 8-11 are taken from "Results of the Blind Analysis Contest 2009" [9], and the test results for Figure 12 are taken from reference 1. 


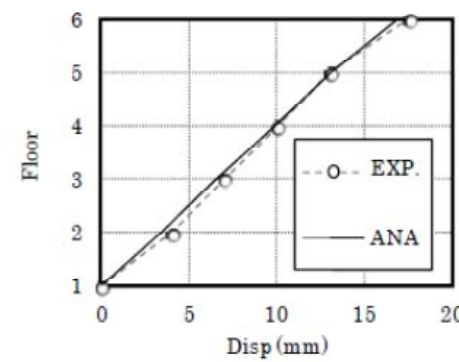

(a)displacement

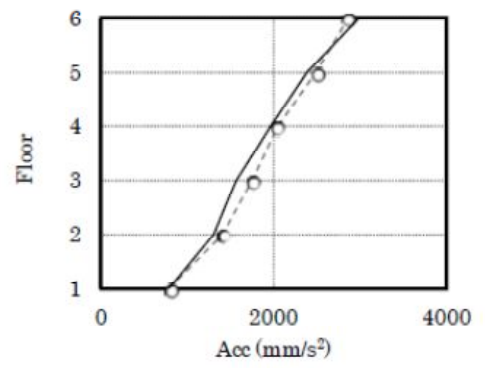

(b)acceleration

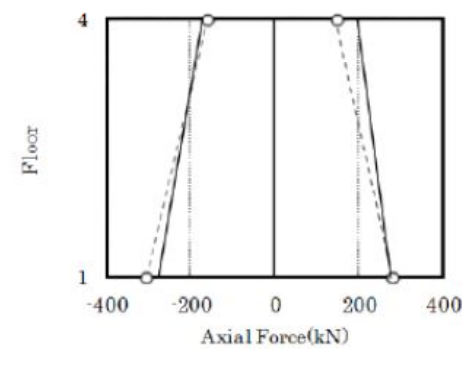

(c) axial force of damper

Figure 8 Comparison of maximum response value(X direction, 15\% input)

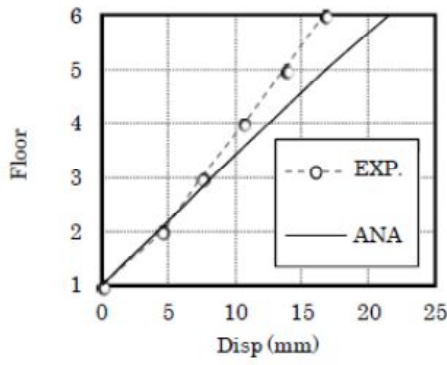

(a)displacement

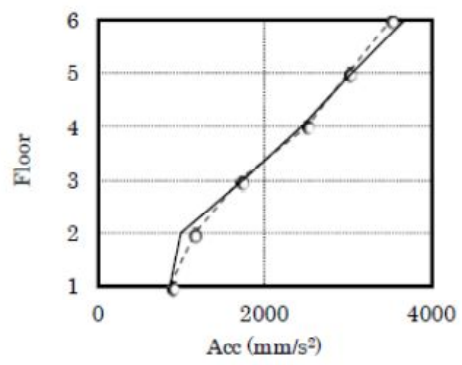

(b)acceleration

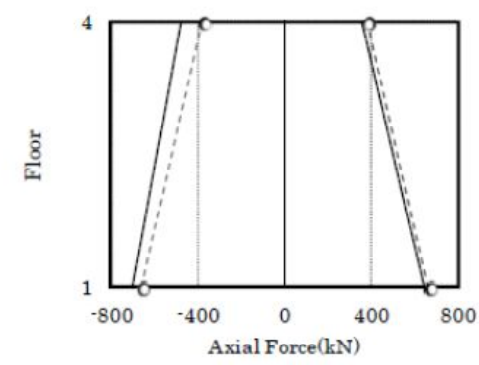

(c)axial force of damper

Figure 9 Comparison of maximum response value(Y direction, 15\% input)

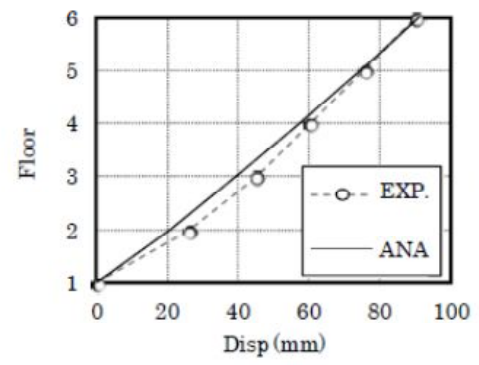

(a)displacement

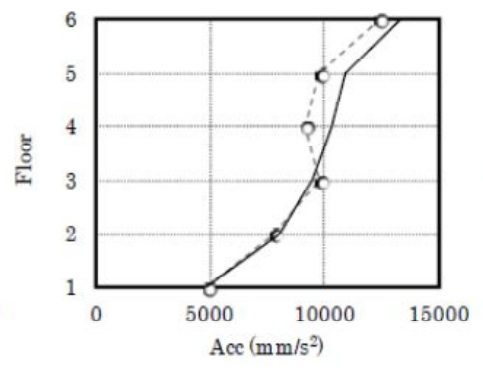

(b)acceleration

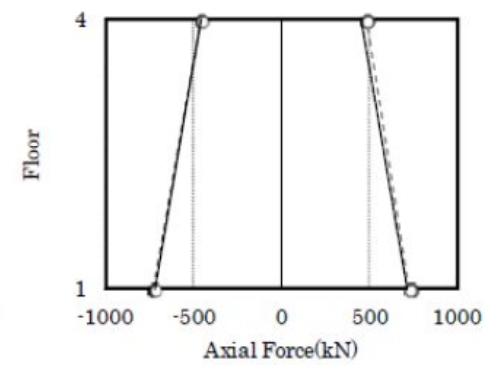

(c)axial force of damper

Figure 10 Comparison of maximum response value(X direction, $100 \%$ input)

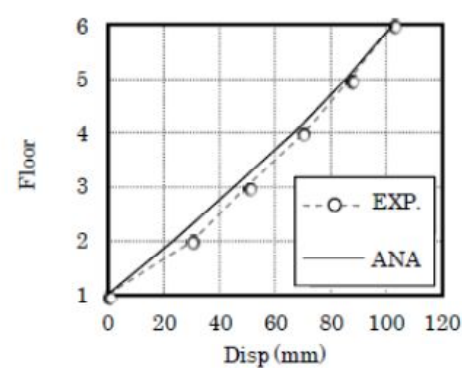

(a)displacement

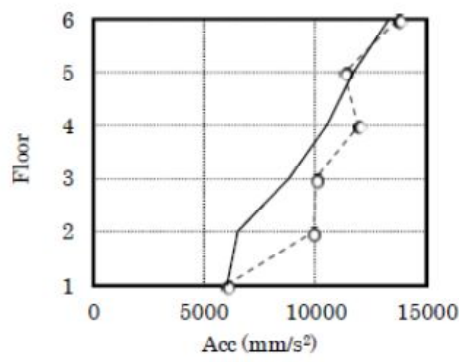

(b)acceleration

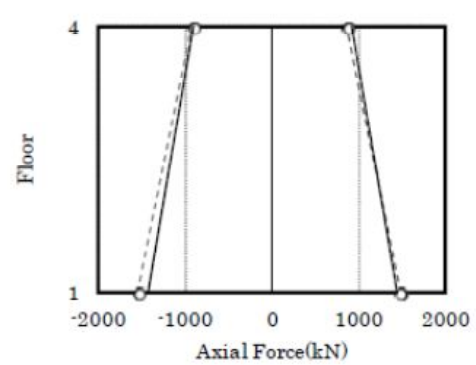

(c)axial force of damper

Figure 11 Comparison of maximum response value(Y direction, 100\% input) 


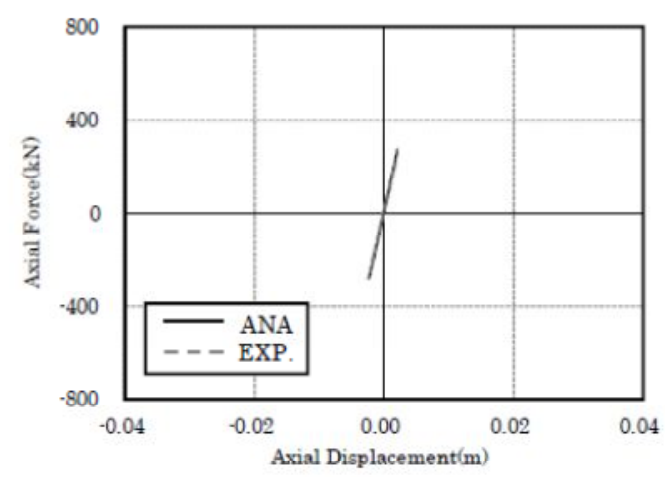

(a) $\mathrm{X}$ direction, $15 \%$ input

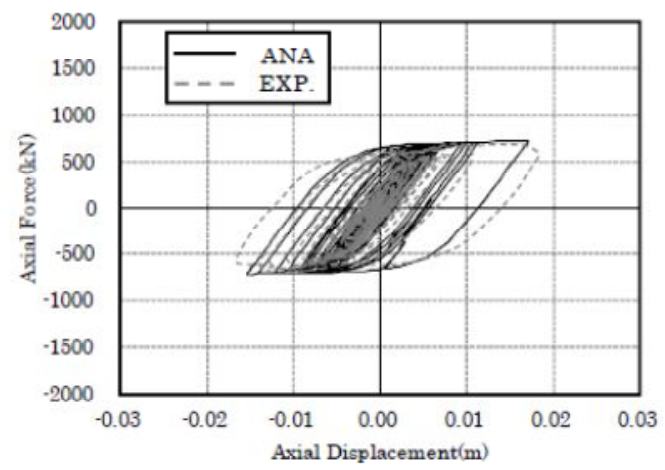

(c)X direction, $100 \%$ input

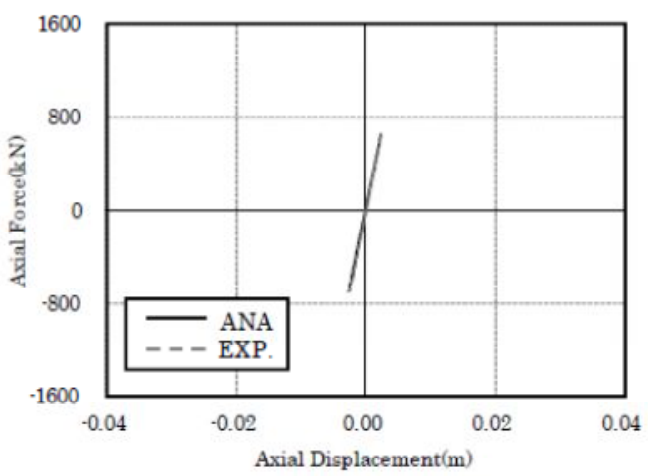

(b)Y direction, $15 \%$ input

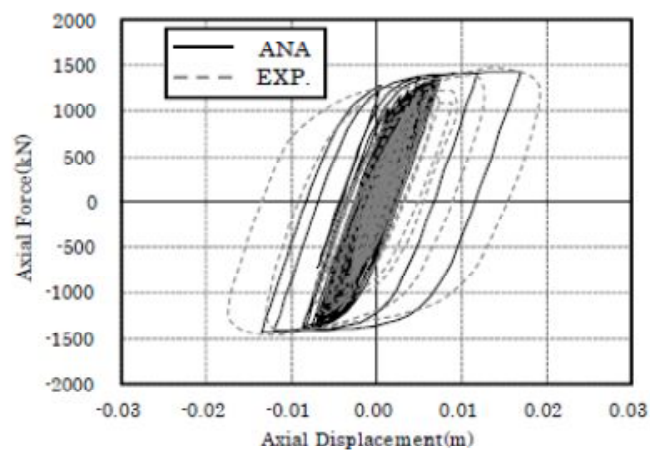

(d)Y direction, $100 \%$ input

Figure 12 Relation between axial force and axial displacement of $1^{\text {st }}$ story

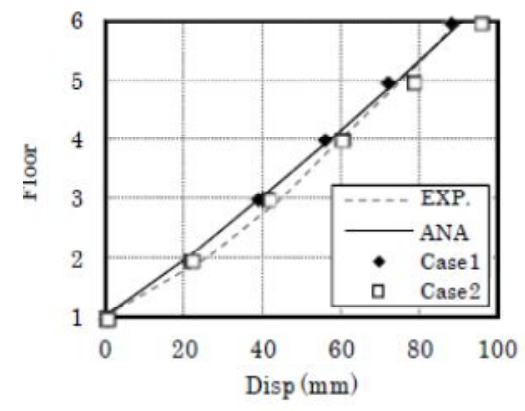

(a)displacement

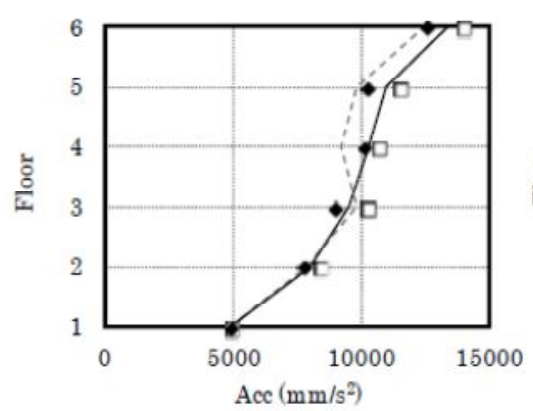

(b)acceleration

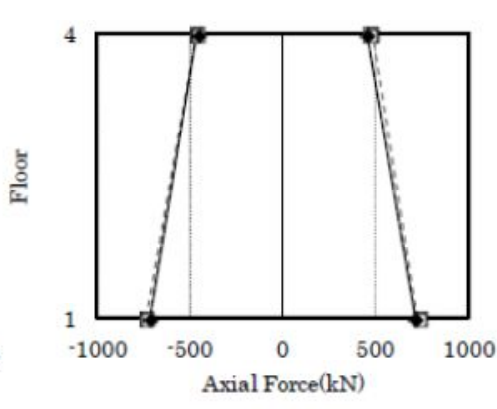

(c)axial force of damper

Figure 13 Comparison of maximum response value ( $\mathrm{X}$ direction)

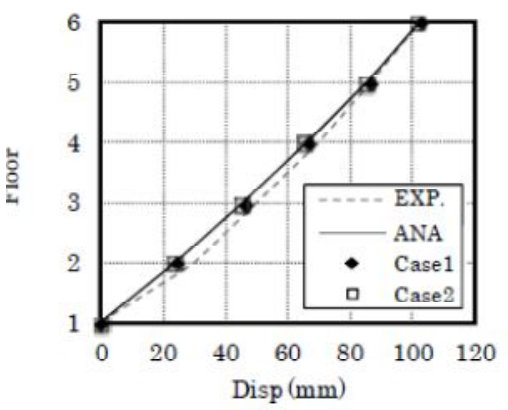

(a)displacement

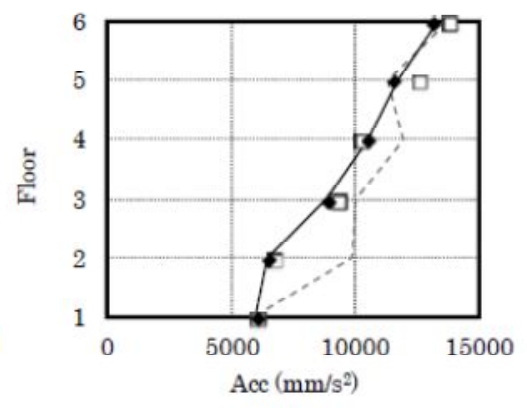

(b)acceleration

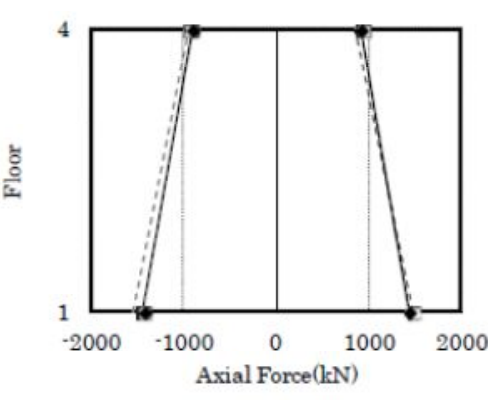

(c)axial force of damper

Figure 14 Comparison of maximum response value (Y direction) 


\section{STUDY OF THE EFFECTS OF RESTORING CHARACTERISTICS AND BEAM- END STIFFNESS}

Although the above prediction analysis results favorably represent the test results in general, the effects on the responses and suitability of the utilized models and parameters are not clearly understood. Hence, we conducted an additional analysis of these factors.

Specifically, we examined the following two points.

1) How much does the scale of the beam-end stiffness set in Section 3.2 influence the response results?

2) How much of a difference occurs when the Menegotto-Pinto model set in Section 3.3 is compared to a simple bilinear model?

Table 8 List of the additional analysis cases

\begin{tabular}{|c|c|c|}
\hline Case name & Hysteresis curve & beam-end stiffness \\
\hline ANA & Menegotto-Pinto & 5 times \\
\hline Case1 & Menegotto-Pinto & 2.5 times \\
\hline Case2 & Bi-Linear & 5 times \\
\hline
\end{tabular}

Table 8 describes a list of the additional analysis cases examined. ANA represents the prediction analysis model. In Case1, the value used in the prediction analysis for beam-end stiffness (originally 5 times) was halved in order to confirm these effects. In Case2, the Menegotto-Pinto model was changed to a normal bilinear model to confirm the effect of the restoring characteristics of the steel dampers. The same series of seismic motion as the prediction analysis were inputted. The results of $100 \%$ inputted that the largest differences appeared are shown.

The maximum response values (displacement and acceleration) at each floor and the axial force of the dampers at the first and fourth floors in the X-direction are compared in Figure 13 and those in the Y-direction are compared in Figure 14. Figure 15 and 16 show the comparison between Case 1 or Case 2 and test results about the relationship between axial force and axial displacement of the first floor.

First, we compared the test results, ANA, and Case1. Case1 replicated the test results relatively well. Especially, the X-direction acceleration response values of the 5 and 6 floors were improved, while ANA could not replicate those results well, shown in Figure 13(b). Except the fact, however, no large differences between Case1 and ANA could be seen in other responses, including Figure 15. Conversely, we conducted a case with double the beam-end stiffness of the ANA, but no significant differences were found.

The reasons for the improved response accuracy when the beam-end stiffness was reduced more than anticipated are considered as follows. Notable reductions in the frame stiffness during excitation were observed during the test. During the Takatori wave excitation of the steel damper structure, the frame stiffness dropped to $85 \%$ of the initial stiffness at $40 \%$ input, and to $75 \%$ of the initial stiffness at $100 \%$ input [1]. The model in this paper did not consider such effects since the frame structure was considered to be an elastic body. Thus, we 
think that a model with a beam stiffness modulus lower than that of Case1 may have had results closer to the results of the tests.

Next, we compared the test results, ANA, and Case2. The maximum responses of Case 2 shown in Figures 13 and 14 tend to show more differences from the test values than the ANA results. In addition, the shape of Case 2 was different from the test values in Figure 16. Thus, we can say that the Menegotto-Pinto model showed higher response accuracy than the bilinear model. However, the differences are not quite large.

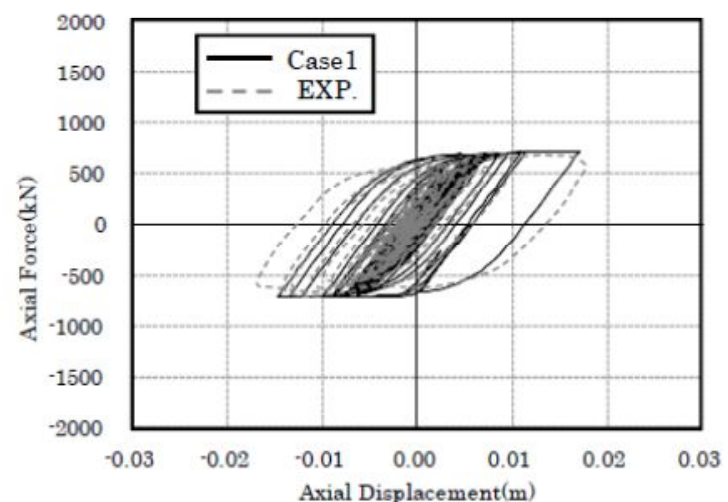

(a) $\mathrm{X}$ direction, $100 \%$ input

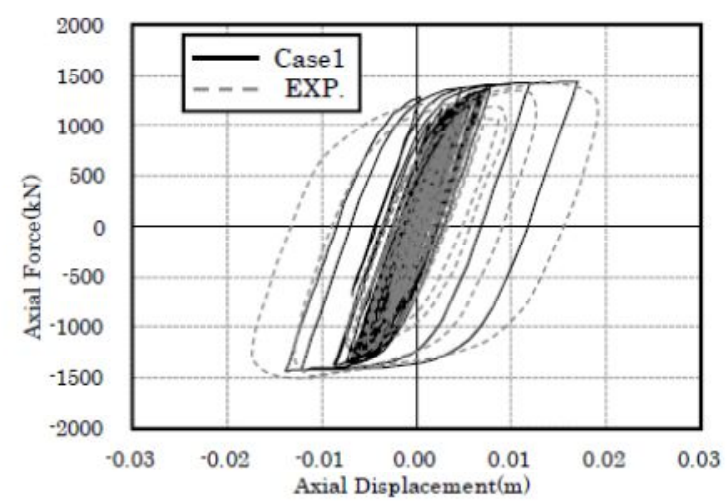

(b)Y direction, $100 \%$ input

Figure 15 Relation between axial force and axial displacement of $1^{\text {st }}$ story

(Comparison between Case1 and EXP)

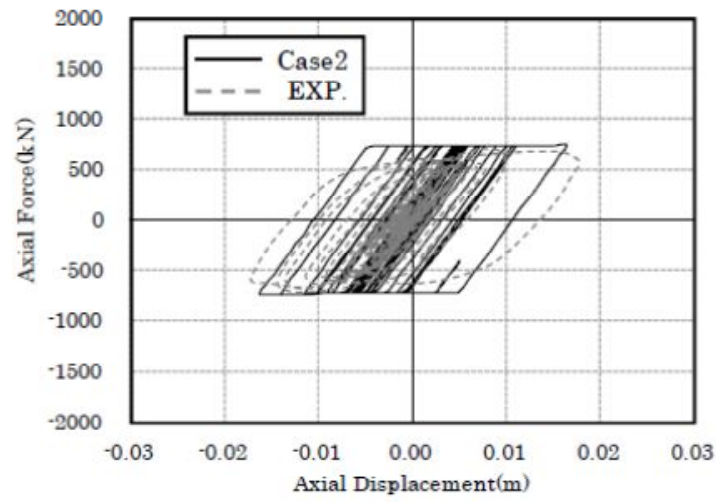

(a)X direction, $100 \%$ input

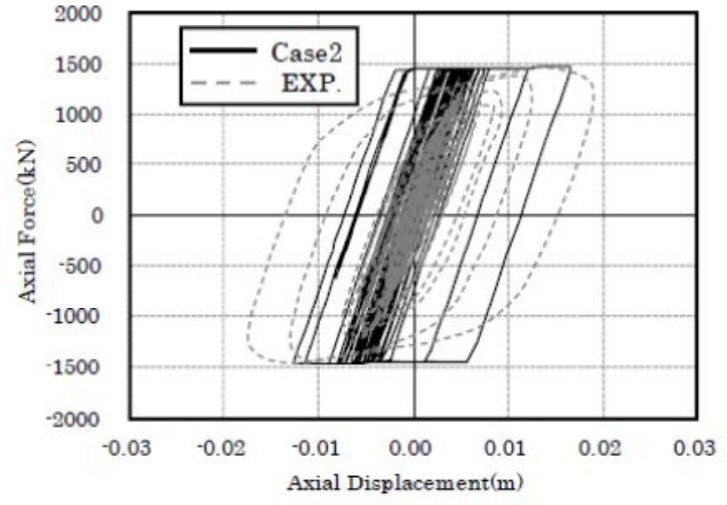

(b)Y direction, $100 \%$ input

Figure 16 Relation between axial force and axial displacement of $1^{\text {st }}$ story

(Comparison between Case2 and EXP) 


\section{CONCLUSIONS}

This paper studied simulation analyses using 3 dimensional models on shaking table test of 5-story steel structures with steel dampers conducted at the E-Defense facility in 2009. The prediction analysis multiplied the beam-end stiffness by 5 to evaluate the stiffness regions of the beam connection panel zones. The Menegotto-Pinto model was used as the restoring characteristics of the steel dampers. As a result, the response values of the analysis favorably replicated the test results.

Next, additional analyses were conducted to study the influence and suitability of these setting values. As a result, a trend in the improvement of response accuracy could be seen when the increase of the beam-end stiffness were reduced. Also, it was shown that the Menegotto-Pinto model used for the restoring characteristics of the dampers contributed to the improved response accuracy when compared to a simple bilinear model.

\section{Acknowledgments}

The research for this paper was conducted in order to participate in the 2009 Blind Analysis Contest held by the E-Defense Steel Structure Research Committee. We wish to thank everyone involved in the testing and the contest.

\section{REFERENCES}

[1] Kasai, K., Ito, H., Ooki, Hikino, T., et al. (2010), "Full-Scale Shake Table Tests of 5Story Steel Building with Various Dampers", 7th International Conference on Urban Earthquake Engineering (7CUEE) \& 5th International Conference on Earthquake Engineering (5ICEE), pp.11-22

[2] Hikino, T., Osaki, M., Kasai, K., Nakashima, M., (2010), "Overview of 2009 E-Defense Blind Analysis Contest Results", 7th International Conference on Urban Earthquake Engineering (7CUEE) \& 5th International Conference on Earthquake Engineering (5ICEE), pp.2153-2158

[3] Nakamura, Y., (1996), "Fault Dynamics of the 1995 Hyogo-ken-nanbu Earthquake Derived from Strong Motion Records", $11^{\text {th }}$ World Conference of Earthquake Engineering, Paper No. 906

[4] Yonetani, M., Azuma, Y., Kasai, K., Kaneko, K., Motoyui, S., (2008), "Hybrid-control Experiments on Full-Scale Subassemblies with Beam-Column-Gusset Connections for Passive-Controlled Steel Buildings : E-Defense Experimental Projects for Steel Buildings - Part 35", Summaries of technical papers of Annual Meeting Architectural Institute of Japan. C-1, 861-862

[5] Kaneko, K., Kasai, K., Azuma, Y., Motoyui, S., (2008), "Post-Buckling Analysis for Subassembly Specimen with Beam-Column-Gusset Connection in Passively-Controlled Steel Structures : E-Defence Experimental Projects for Steel Buildings - Part 38”, 
Summaries of technical papers of Annual Meeting Architectural Institute of Japan. C-1, 867-868

[6] Matsuoka, Y., Mccormick, J., Suita, K., Nakashima, M., (2008), "Seismic Response of Non-Structural Partition Walls and Hanging Ceiling Systems", Journal of structural and construction engineering. Transactions of AIJ 73(632), 1857-1864

[7] Yamazaki, H., Kazuhiko, K., Ono, Y., (2005), "Curved Hysteresis Model of Structural Steel under Cyclic Loading: Part 1 Analytical Model”, Summaries of technical papers of Annual Meeting Architectural Institute of Japan. C-1, 745-746

[8] National Research Institute for Earth Science and Disaster Prevention, (2009a), "Web site of Blind Analysis Contest 2009”, <http://www.blind-analysis.jp/index.html>

[9] National Research Institute for Earth Science and Disaster Prevention, (2009b), "Results of the Blind Analysis Contest 2009", <http://www.blindanalysis.jp/kekka/2009BA_e.pdf> 